\title{
Two-Year Outcomes after Conventional or Endovascular Repair of Abdominal Aortic Aneurysms
}

\begin{abstract}
Jan D. Blankensteijn, M.D., Sjors E.C.A. de Jong, M.D., Monique Prinssen, M.D., Arie C. van der Ham, M.D., Jaap Buth, M.D., Steven M.M. van Sterkenburg, M.D., Hence J.M. Verhagen, M.D., Erik Buskens, M.D., and Diederick E. Grobbee, M.D., for the Dutch Randomized Endovascular Aneurysm Management
\end{abstract}

(DREAM) Trial Group*
From the Department of Vascular Surgery, Radboud University Nijmegen Medica Center, Nijmegen (J.D.B., S.E.C.A.J.); the Division of Vascular Surgery, Department of Surgery (M.P., H.J.M.V.), and the Julius Center for Health Sciences and Primary Care (S.E.C.A.J., E.B., D.E.G.), University Medical Center, Utrecht; the Department of Surgery, St. Franciscus Gasthuis, Rotterdam (A.C.H.); the Department of Surgery, Catharina Hospital, Eindhoven (J.B.) and the Department of Surgery, Rijnstate Hospital, Arnhem (S.M.M.S.) - all in the Netherlands. Address reprint requests to Dr. Blankensteijn at the Department of Vascular Surgery (410), Radboud University Nijmegen Medical Center, P.O. Box 9101, 6500 HB Nijmegen, the Netherlands, or at j.blankensteijn@chir.umcn.nl.

*The members of the DREAM Trial Group are listed in the Appendix.

N Engl J Med 2005;352:2398-405. Copyright ( 2005 Massachusetts Medical Society.

\section{ABSTRACT}

BACKGROUND

Two randomized trials have shown better outcomes with elective endovascular repair of abdominal aortic aneurysms than with conventional open repair in the first month after the procedure. We investigated whether this advantage is sustained beyond the perioperative period.

\section{METHODS}

We conducted a multicenter, randomized trial comparing open repair with endovascular repair in 351 patients who had received a diagnosis of abdominal aortic aneurysm of at least $5 \mathrm{~cm}$ in diameter and who were considered suitable candidates for both techniques. Survival after randomization was calculated with the use of Kaplan-Meier analysis and compared with the use of the log-rank test on an intention-to-treat-basis.

\section{RESULTS}

Two years after randomization, the cumulative survival rates were 89.6 percent for open repair and 89.7 percent for endovascular repair (difference, -0.1 percentage point; 95 percent confidence interval, -6.8 to 6.7 percentage points). The cumulative rates of aneurysm-related death were 5.7 percent for open repair and 2.1 percent for endovascular repair (difference, 3.7 percentage points; 95 percent confidence interval, -0.5 to 7.9 percentage points). This advantage of endovascular repair over open repair was entirely accounted for by events occurring in the perioperative period, with no significant difference in subsequent aneurysm-related mortality. The rate of survival free of moderate or severe complications was also similar in the two groups at two years (at 65.9 percent for open repair and 65.6 percent for endovascular repair; difference, 0.3 percentage point; 95 percent confidence interval, -10.0 to 10.6 percentage points).

CONCLUSIONS

The perioperative survival advantage with endovascular repair as compared with open repair is not sustained after the first postoperative year. 
T

WO RANDOMIZED TRIALS HAVE DEMonstrated better outcomes with elective endovascular repair of abdominal aortic aneurysms than with conventional open repair in the first month after the procedure. ${ }^{1,2}$ The reported in-hospital mortality rates in these two trials were 4.6 percent and 6.0 percent for open repair and 1.6 percent and 1.2 percent for endovascular repair, respectively. Although the relevance of a reduction in perioperative risk should not be underestimated from the patient's perspective, the improvement in early survival with the use of a less invasive technique is not surprising. ${ }^{3}$ Consequently, both reports stressed the need for longer-term data before a decision could be reached about which therapy is better in patients who are suitable candidates for either procedure.

Findings in uncontrolled long-term studies of endovascular aneurysm repair have suggested that the early advantage of endovascular over open repair may not persist over time. ${ }^{4,5}$ Endovascular repair appeared to be associated with higher rates of reintervention and complications as well as a continued risk of aneurysm rupture. The Dutch Randomized Endovascular Aneurysm Management (DREAM) trial was conducted to assess the rates of death from any cause and complications in a multicenter, randomized trial comparing elective open and endovascular aneurysm repair.

METHODS

\section{STUDY DESIGN AND PATIENTS}

The design and methods of the trial have been described in detail elsewhere. ${ }^{2,6}$ In brief, patients referred to surgery clinics at 26 centers in the Netherlands and 4 centers in Belgium who had received a diagnosis of an abdominal aortic aneurysm of at least $5 \mathrm{~cm}$ in diameter and who were considered suitable candidates for both techniques were randomly assigned to undergo open or endovascular repair after giving written informed consent. Randomization was carried out centrally with the use of a computer-generated permuted-block sequence and stratified according to study center in blocks of four patients.

The study was performed according to the principles of the Declaration of Helsinki. The institutional review boards of all participating hospitals approved the protocol. The corresponding author assumed full responsibility for the conduct of the trial, had full access to all the data, and controlled the decision to publish. The study was publicly funded, and the sponsor had no role in the study design.

\section{DATA COLLECTION AND FOLLOW-UP}

All data were submitted to the trial-coordination center (Julius Center for Health Sciences and Primary Care, University Medical Center, Utrecht, the Netherlands). Follow-up visits were scheduled 30 days and 6,12, 18, and 24 months after the procedure. Before hospital discharge and at each follow-up visit, all patients underwent a physical examination, which included calculation of the ankle-brachial blood-pressure index; abdominal helical computed tomographic angiography; and abdominal color duplex ultrasonography. In addition, patients in the endovascular group underwent plain abdominal radiography before hospital discharge and 12 and 24 months postoperatively.

Data acquisition was stopped on March 1, 2005, for this report. For all analyses, data on patients were censored after their last follow-up visit. For the crude survival analysis, however, reports on vital status obtained at any time before the cutoff date were also incorporated.

\section{END POINTS}

The primary end point of the trial was a composite of operative mortality and moderate or severe complications, as discussed in the initial report on the results of the trial. ${ }^{2}$ Mortality and complications at two years were predetermined secondary end points in the original trial design. The outcome events that we analyzed were deaths from all causes, aneurysmrelated deaths, complications, and reinterventions.

The cause and exact date of death were determined by assessment of death certificates and by contacting the physicians involved (surgeons and general practitioners) and patients' relatives if necessary. Aneurysm-related death was defined as death resulting from aneurysm rupture, graft infection, or thrombosis; any death occurring within 30 days after the original procedure or a reintervention; or any death occurring more than 30 days after the original procedure or a reintervention but during the same admission.

Complications were classified and graded according to the reporting standards of the Ad Hoc Committee for Standardized Reporting Practices in Vascular Surgery of the Society for Vascular Surgery/International Society for Cardiovascular Surgery. ${ }^{7,8}$ Three severity grades (mild, moderate, and 
severe) were distinguished. Mild complications were not considered in this analysis. A reintervention was defined as any surgical or endovascular procedure performed after the primary aneurysmrepair procedure and related to the aneurysm or the primary procedure, including incisional hernia repairs but exclusive of procedures involving superficial wound complications. An outcome

\begin{tabular}{|c|c|c|}
\hline Characteristic & $\begin{array}{c}\text { Open } \\
\text { Repair } \\
(\mathrm{N}=178)\end{array}$ & $\begin{array}{c}\text { Endovascular } \\
\text { Repair } \\
(\mathrm{N}=173)\end{array}$ \\
\hline Age $-y r$ & $69.6 \pm 6.8$ & $70.7 \pm 6.6$ \\
\hline Male sex — no. (\%) & $161(90.4)$ & $161(93.1)$ \\
\hline \multicolumn{3}{|l|}{$\begin{array}{l}\text { Mild, moderate, or severe SVS/ISCVS } \\
\text { risk-factor score }-\% \dagger\end{array}$} \\
\hline Diabetes mellitus & 9.6 & 10.4 \\
\hline Tobacco use & 55.1 & 64.2 \\
\hline Hypertension & 54.5 & 58.4 \\
\hline Hyperlipidemia & 52.6 & 47.0 \\
\hline Carotid artery disease & 15.2 & 14.5 \\
\hline Cardiac disease & 46.6 & 41.0 \\
\hline Renal disease & 8.4 & 7.5 \\
\hline Pulmonary disease & 18.5 & 27.7 \\
\hline Total SVS/ISCVS risk-factor score† & $4.5 \pm 2.5$ & $4.4 \pm 2.5$ \\
\hline $\mathrm{FEV}_{1}$ - liters $/ \mathrm{sec}$ & $2.6 \pm 0.7$ & $2.5 \pm 0.7$ \\
\hline Body-mass index & $26.6 \pm 4.1$ & $26.3 \pm 3.4$ \\
\hline \multicolumn{3}{|l|}{ ASA class — no. (\%) } \\
\hline I (healthy status) & $44(24.7)$ & $37(21.4)$ \\
\hline II (mild systemic disease) & $110(61.8)$ & $122(70.5)$ \\
\hline III (severe systemic disease) & $24(13.5)$ & $14(8.1)$ \\
\hline \multicolumn{3}{|l|}{ Medication use - no. (\%) } \\
\hline Beta-blockers & $92(51.7)$ & $76(43.9)$ \\
\hline Statinsł & $72(41.9)$ & $63(37.3)$ \\
\hline Antiplatelet agents & $72(40.4)$ & $70(40.5)$ \\
\hline Angiotensin-converting-enzyme inhibitors & $50(28.1)$ & $58(33.5)$ \\
\hline Calcium-channel blockers & $32(18.0)$ & $30(17.3)$ \\
\hline Anticoagulants & $27(15.2)$ & $20(11.6)$ \\
\hline
\end{tabular}

* Plus-minus values are means $\pm S D$. There were no significant differences between the groups. $\mathrm{FEV}_{1}$ denotes forced expiratory volume in one second, and ASA American Society of Anesthesiologists. The body-mass index is the weight in kilograms divided by the square of the height in meters. Because of rounding, not all percentages total 100 .

$\dagger$ The Society for Vascular Surgery/International Society for Cardiovascular Surgery (SVS/ISCVS) risk-factor score is calculated for eight domains, and scores for each domain can range from 0 (no risk factors) to 3 (severe risk factors). ${ }^{7}$ Total scores can range from 0 to 24, with higher scores indicating greater risk. $\neq$ No information on the use of statins was available for six patients in the openrepair group and four patients in the endovascular-repair group. adjudication committee, consisting of five vascular surgeons, assessed the type and severity of each complication and reintervention in a blinded fashion and independently from each other. Disagreements were resolved in a plenary consensus meeting.

\section{STATISTICAL ANALYSIS}

All data were analyzed according to the intentionto-treat principle. Kaplan-Meier analysis was used to analyze survival and other end points, and differences between groups were compared with the use of the log-rank test. Cox proportional-hazards regression was used to estimate hazard ratios for the analysis of reintervention rates. Means $( \pm S D)$ were used to describe continuous variables. Differences between groups were compared with the use of the Mann-Whitney U test for continuous variables and Fisher's exact test for proportions. All reported $P$ values are two-sided and are not adjusted for multiple testing.

\section{RESULTS}

CHARACTERISTICS OF THE PATIENTS AND TREATMENT ASSIGNMENTS

Between November 2000 and December 2003, 178 patients were randomly assigned to undergo open repair and 173 to undergo endovascular repair. Six patients did not undergo aneurysm repair after randomization: four declined treatment (three assigned to open repair and one to endovascular repair), one died from a ruptured abdominal aortic aneurysm before undergoing open repair, and one died from pneumonia before undergoing endovascular repair. There were six crossovers: five patients who were randomly assigned to undergo open repair underwent endovascular repair, and one patient assigned to endovascular repair underwent open repair. Overall, the operation was started according to the randomized assignment in 96.6 percent of patients (339 of 351).

The baseline characteristics of the patients are given in Table 1. Demographic characteristics, the prevalence of coexisting conditions, cardiovascularrisk profiles, the distribution of American Society of Anesthesiologists risk classes, and medication use were similar in the two groups.

The median interval between randomization and the procedure was 39 days in both the open-repair group (range, 4 to 260) and the endovascularrepair group (range, 1 to $183 ; \mathrm{P}=0.76$ ); 92.6 percent 
of patients (325 of 351) underwent aneurysm repair within 3 months after randomization. The mean duration of follow-up was 21 months in the open-repair group (range, 0 to 39) and 22 months in the endovascular-repair group (range, 1 to 42). A total of 6 patients were lost to follow-up during the first year (follow-up 98.3 percent complete) and 19 during the first two years (follow-up 94.6 percent complete).

\section{MORTALITY}

Two years after randomization, the cumulative survival rates were 89.6 percent for open repair and 89.7 percent for endovascular repair, for a difference of -0.1 percentage point ( 95 percent confidence interval, -6.8 to 6.7 percentage points; $\mathrm{P}=0.86$ ) (Fig. 1). The small but apparent survival advantage in the first year after endovascular repair did not reach statistical significance $(\mathrm{P}=0.15)$ and appeared to be based entirely on a decreased rate of in-hospital (perioperative) mortality.

There was one preoperative death and eight inhospital deaths in the open-repair group and one preoperative and two in-hospital deaths in the endovascular-repair group (Table 2). Taking into account the patients who declined treatment (three in the open-repair group and one in the endovascularrepair group), there were 166 discharges after open repair and 169 discharges after endovascular repair. The causes of death are listed in Table 2. After discharge, there were more deaths from cardiovascular causes in the endovascular-repair group than in the open-repair group (six vs. three), although this difference was not significant $(\mathrm{P}=0.50)$.

There was an unexplained cluster of deaths in the endovascular-repair group approximately one year after randomization (Fig. 1). None of these deaths were considered to be aneurysm-related as defined in the Methods section; two of the deaths were due to heart failure, one to acute cardiac arrest, one to stroke, and one to aspiration pneumonia in a patient with metastatic carcinoma of the bladder.

\section{ANEURYSM-RELATED MORTALITY}

The cumulative rates of aneurysm-related death two years after randomization were 5.7 percent in the open-repair group and 2.1 percent in the endovascular-repair group, for a difference of 3.7 percentage points ( 95 percent confidence interval, -0.5 to 7.9 percentage points; $\mathrm{P}=0.05$ ). The difference in aneurysm-related mortality at two years was based

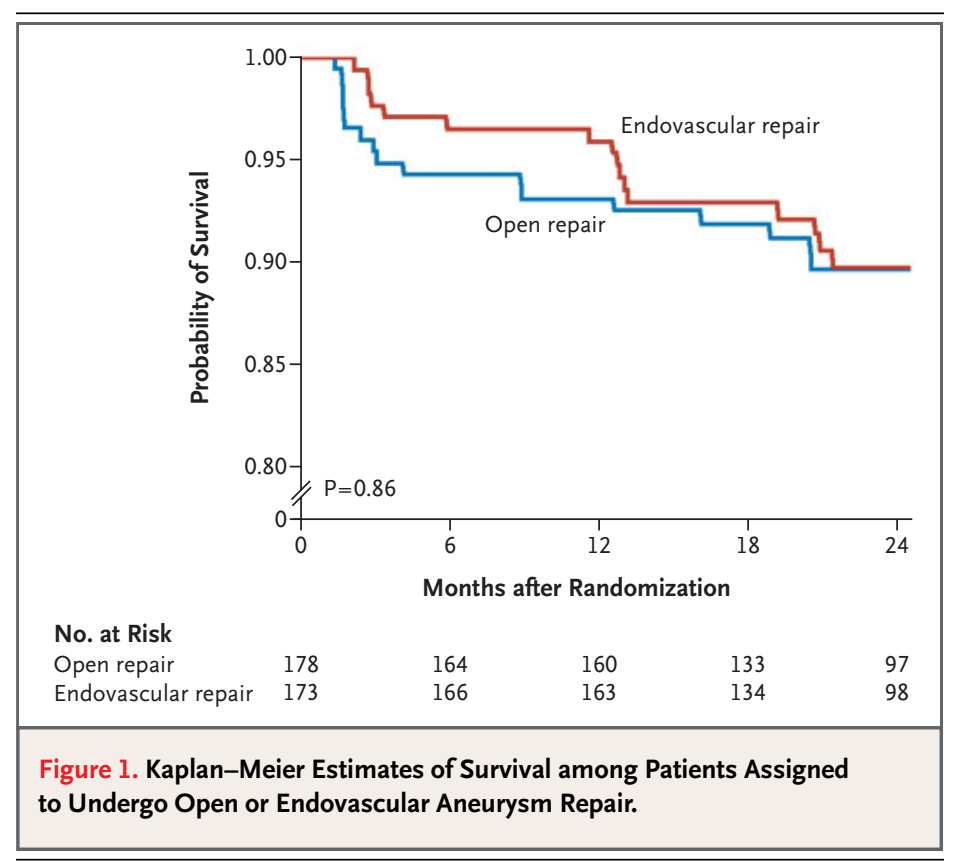

entirely on the difference in in-hospital (perioperative) mortality. After discharge, only one additional aneurysm-related death occurred in each group (Table 2).

\section{COMPLICATIONS}

Two years after randomization, the rates of survival free of severe events were 80.6 percent for open repair and 83.1 percent for endovascular repair, for a difference of -2.5 percentage points $(95$ percent confidence interval, -10.9 to 5.9 percentage points; $\mathrm{P}=0.39$ ) (Fig. 2). As with the data on aneurysmrelated mortality, the difference in the rate of survival free from severe events at two years was based entirely on the difference in in-hospital events. The rates of survival free of moderate or severe events two years after randomization were 65.9 percent for open repair and 65.6 percent for endovascular repair, for a difference of 0.3 percentage point $(95$ percent confidence interval, -10.0 to 10.6 percentage points; $\mathrm{P}=0.88$ ).

There were no documented postoperative aneurysm ruptures. However, in two patients who died after endovascular repair, the possibility of aneurysm rupture was considered but not proved (Table 2).

Kaplan-Meier estimates of the likelihood of freedom from reintervention are shown in Figure 3. In the first nine months after randomization, the rate of reintervention after endovascular repair was al- 


\begin{tabular}{|c|c|c|c|c|c|c|c|c|}
\hline \multirow[t]{3}{*}{ Cause of Death } & \multicolumn{2}{|c|}{ Before Surgery*: } & \multicolumn{2}{|c|}{ In the Hospitali } & \multicolumn{2}{|c|}{ After Discharge } & \multicolumn{2}{|c|}{ Overall } \\
\hline & $\begin{array}{c}\text { Open } \\
\text { Repair } \\
(\mathrm{N}=178)\end{array}$ & $\begin{array}{c}\text { Endovascular } \\
\text { Repair } \\
(\mathrm{N}=173)\end{array}$ & $\begin{array}{c}\text { Open } \\
\text { Repair } \\
(\mathrm{N}=174)\end{array}$ & $\begin{array}{c}\text { Endovascular } \\
\text { Repair } \\
(\mathrm{N}=171)\end{array}$ & $\begin{array}{c}\text { Open } \\
\text { Repair } \\
(\mathrm{N}=166)\end{array}$ & $\begin{array}{c}\text { Endovascular } \\
\text { Repair } \\
(\mathrm{N}=169)\end{array}$ & $\begin{array}{c}\text { Open } \\
\text { Repair } \\
(\mathrm{N}=178)\end{array}$ & $\begin{array}{c}\text { Endovascular } \\
\text { Repair } \\
(\mathrm{N}=173)\end{array}$ \\
\hline & \multicolumn{8}{|c|}{ number of patients } \\
\hline All causes & 1 & 1 & 8 & 2 & 9 & 17 & 18 & 20 \\
\hline Cardiovascular causes & 0 & 0 & 2 & 1 & 3 & 6 & 5 & 7 \\
\hline Myocardial infarction & 0 & 0 & 1 & 1 & 0 & 1 & 1 & 2 \\
\hline Cardiac arrest & 0 & 0 & 1 & 0 & 2 & 2 & 3 & 2 \\
\hline Congestive heart failure & 0 & 0 & 0 & 0 & 0 & 2 & 0 & 2 \\
\hline Stroke & 0 & 0 & 0 & 0 & 1 & 1 & 1 & 1 \\
\hline $\begin{array}{l}\text { Aneurysm-related, noncar- } \\
\text { diovascular causes }\end{array}$ & 1 & 0 & $6 \%$ & $1 \rrbracket$ & 19 & $1 \|$ & 8 & 2 \\
\hline Cancer & 0 & 0 & 0 & 0 & 2 & 4 & 2 & 4 \\
\hline Other & 0 & 1 & 0 & 0 & $1 * *$ & $4 \dagger$ & 1 & 5 \\
\hline Unknown & 0 & 0 & 0 & 0 & $2+$ & $2 \iint \sqrt{\int}$ & 2 & 2 \\
\hline
\end{tabular}

* Two patients died before undergoing the assigned operation: one patient with preexistent pulmonary fibrosis assigned to undergo endovascular repair died from pneumonia 84 days after randomization, and one patient assigned to undergo open repair died from a ruptured abdominal aortic aneurysm.

$\dagger$ In-hospital data were reported previously. ${ }^{2}$ All 10 in-hospital deaths were aneurysm-related by definition. None of the nine deaths from cardiovascular causes after discharge were aneurysm-related.

$\mp$ The causes of death were as follows: infection of the prosthesis, anastomotic bleeding, ischemic bowel, intraoperative anaphylactic shock, multiorgan failure after repair of a burst abdomen, and progressive dementia and refusal to eat or drink leading to respiratory insufficiency and death.

$\int$ The cause of death was bilateral pneumonia.

I The cause of death was peritonitis resulting from an iatrogenic bowel lesion during repeated operation to correct prosthetic malalignment.

$\|$ The cause of death was an infected endograft.

**: The cause of death was pneumonia.

†TThe causes of death were as follows: peritonitis, pulmonary embolism, respiratory insufficiency, and general deterioration related to old age.

No data were available on the cause of death.

If Both patients died suddenly, 33 and 41 months after the procedure. A ruptured aneurysm was considered a possible cause of death, but in neither patient was a postmortem examination performed. Both patients had evidence of a shrinking aneurysm sac on their last (24-month) follow-up computed tomographic scan.

most three times the rate after open repair (hazard ratio, 2.9; 95 percent confidence interval, 1.1 to $6.2 ; \mathrm{P}=0.03)$. Thereafter, reintervention rates were roughly parallel (hazard ratio, 1.1; 95 percent confidence interval, 0.1 to $9.3 ; \mathrm{P}=0.95$ ).

\section{DISCUSSION}

We found that by the end of the first year after randomization, the previously reported perioperative survival advantage of endovascular aneurysm repair over open repair was no longer apparent. ${ }^{2} \mathrm{Al}-$ though a lower rate of aneurysm-related death after endovascular repair did appear to be maintained during the first two years, in terms of overall survival, this was cancelled out by excess mortality from other causes, including cardiovascular causes, in the first two years after discharge.
One other randomized trial, the Endovascular Aneurysm Repair (EVAR-1) trial, has compared the results of endovascular aneurysm repair with those of open repair. ${ }^{1}$ Whereas the early results of the two trials were similar, the long-term results of EVAR- 1 are not yet available and thus cannot be compared with our findings.

Our results are similar to those of two recently reported retrospective, controlled studies comparing endovascular and open repair. ${ }^{9,10}$ In both studies, the respective one-year survival rates after open and endovascular repair were approximately 92 and 95 percent, and the respective two-year survival rates were approximately 88 and 89 percent, all of which are very close to our findings. The rates of aneurysm-related death two years after open and endovascular repair were 4.2 and 0.9 percent, respectively, in the study by Cao et al. ${ }^{10}$ as compared 
with 5.7 and 2.1 percent, respectively, in our study. It is possible that the prospective nature of our study allowed for more complete detection of aneurysm-related deaths. The difference in reintervention rates between the groups in our study is also similar to that reported in both retrospective studies. In one study, the divergence of reintervention rates did not start until after two years of followup, ${ }^{10}$ whereas in our study, there was no significant difference in reintervention rates beyond nine months after randomization. This variation may depend on how aggressively certain complications are addressed.

Although our findings - and those in the other trials discussed above - suggest that endovascular aneurysm repair may provide an early survival advantage over conventional surgery, it appears that this advantage is lost by the end of the first year. It is unknown whether the durability of the endovascular graft will jeopardize long-term outcomes. Although nonrandomized, follow-up studies of patients who have undergone aneurysm repair have failed to show a long-term advantage of open over endovascular repair, ${ }^{9,10}$ concerns persist, since the rates of aneurysm-related death and reintervention after endovascular repair have been reported to continue to increase over time. ${ }^{4,11}$ The overall survival curves in our trial appeared to converge in the second year after randomization. Our 2-year data do not exclude the possibility that these curves will actually cross, resulting in a higher rate of death for endovascular repair than for open repair after 24 months.

There may be two possible explanations for the convergence of survival curves in our study. One is that patients who have survived the stress of open repair may be somewhat less likely to die in the first few months after surgery than patients who have undergone endovascular repair, since the latter group has not been subjected to a conventional surgical procedure. In other words, the survival advantage resulting from a less-invasive approach to aneurysm repair may largely be based on postponing death among higher-risk patients from the perioperative period to the subsequent months. Although patients in our trial had to be eligible to undergo conventional open aneurysm repair before they could undergo randomization, the health of patients with abdominal aortic aneurysms is often seriously compromised by other types of cardiovascular disease. In our study, 58 percent of the deaths (22 of 38) were due to either cardiovascular causes
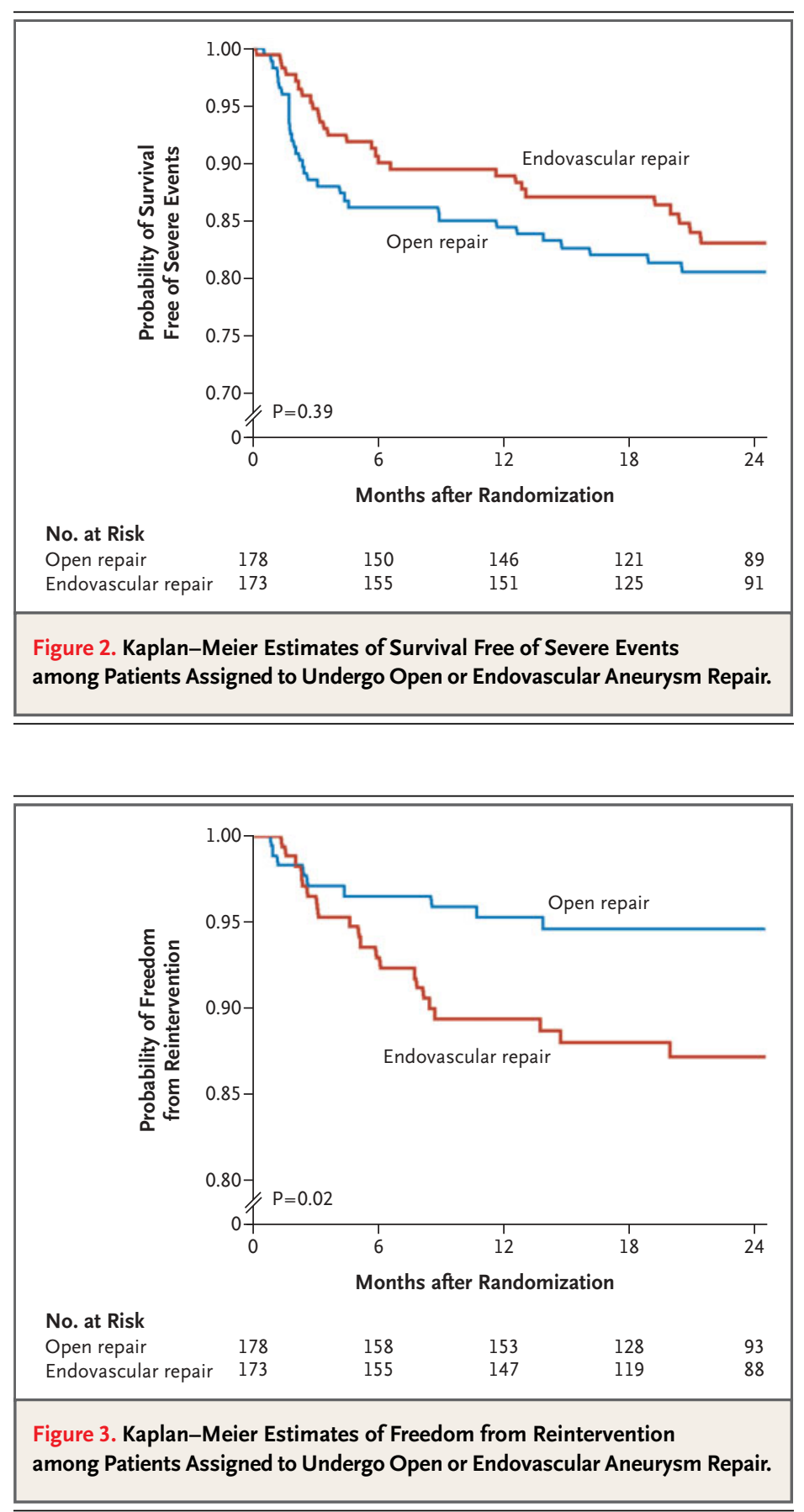

or causes related to aneurysm repair. This finding is in accordance with those of other follow-up studies of aneurysm repair. ${ }^{12,13}$

Another possible explanation for the convergence of survival curves is the failure of endovascular repair to prevent rupture of the aneurysm. However, endograft failure is unlikely to occur during the first two years after implantation, and such fail- 
ure would be reflected by a convergence of the rates of aneurysm-related death - an effect that was not found in our analysis. Although a grouping of deaths was seen in the endovascular-repair group about one year after randomization, the causes of death were not related to the aneurysm. Furthermore, the apparent grouping of these deaths was seen in a Kaplan-Meier survival analysis that measured the time from randomization, rather than the time from the procedure, indicating that this grouping of deaths was not related to the course after intervention. Only one patient in the endovascular-repair group died of an aneurysm-related cause (an infected endograft) after hospital discharge. Whether the rate of graft failure will increase with further follow-up remains to be seen.

In patients undergoing endovascular repair, efforts should be made to maintain the survival advantage associated with avoiding conventional surgery. This effort may at least in part be a matter of strict risk-factor management. Beta-blockers, anti- platelet agents, and statins were each being used in less than 50 percent of our patients at baseline. Clearly, less-than-optimal medication was used in view of current guidelines on risk management for patients with manifestations of atherosclerosis. ${ }^{14-16}$ Of course, better perioperative and postoperative management of risk factors could also improve the results of open aneurysm repair.

In conclusion, the two-year results of the DREAM trial indicate that the perioperative survival advantage with endovascular repair as compared with open repair is limited to the first postoperative year.

Supported by a grant (OG 98-068) from the Netherlands National Health Insurance Council.

Dr. Buth reports having received lecture fees from Medtronic; Dr. Verhagen, consulting fees from W.L. Gore and Associates, Medtronic, and Edwards Lifesciences; Dr. de Jong, a travel grant from W.L. Gore and Associates; and Dr. Buskens, consulting fees from PharMerit.

We are indebted to the Netherlands Society for Vascular Surgery for its support and to Nicole Boekema for her outstanding efforts in data management.

A P PENDIX

The members of the DREAM Trial Group were as follows: Steering Committee: D.E. Grobbee, J.D. Blankensteijn, A.A.A. Bak, J. Buth, P.M. Pattynama, E.L.G. Verhoeven, A.E. van Voorthuisen; Executive and Writing Committee: J.D. Blankensteijn, J. Buth, E. Buskens, D.E. Grobbee, A.C. van der Ham, S.E.C.A. de Jong, M. Prinssen, S.M.M. van Sterkenburg, H.J.M. Verhagen; Data-Monitoring and Ethics Committee: M.G. Hunink, J.M. van Engelshoven, M.J.H.M. Jacobs, B.A.J.M de Mol; Site and Device-Selection Committee: J.H. van Bockel, R. Balm, J. Reekers, X. Tielbeek, E.L.G. Verhoeven, W. Wisselink; Data Management: N. Boekema, I Sikking; Outcome Adjudication Committee: M. Prinssen, R. Balm, J.D. Blankensteijn, J. Buth, M.R.H.M. van Sambeek, E.L.G. Verhoeven; Data Analysis: J.D. Blankensteijn, E. Buskens, S.E.C.A. de Jong; Clinical Centers (the number of randomized patients is given in parentheses): the Netherlands: Catharina Hospital, Eindhoven (94) — J. Buth, A.V. Tielbeek; University Medical Center, Utrecht (35) - J.D. Blankensteijn; Academic Medical Center, Amsterdam (32) - R. Balm, J.A. Reekers; Erasmus Medical Center, Rotterdam (30) - M.R.H.M. van Sambeek, P. Pattynama; University Hospital, Groningen (27) - E.L.G. Verhoeven, T. Prins; St. Franciscus Gasthuis, Rotterdam (27) - A.C. van der Ham, J.J.I.M. van der Velden; Rijnstate Hospital, Arnhem (14) - S.M.M. van Sterkenburg, G.B. ten Haken; Leyenburg Hospital, 's-Gravenhage (9) - C.M.A. Bruijninckx, H. van Overhagen; Albert Schweitzer Hospital, Dordrecht (8) — R.P. Tutein Nolthenius, T.R. Hendriksz; Atrium Medical Center, Heerlen (8) - J.A.W. Teijink, H.F. Odink; Medical Center Rijnmond Zuid, Rotterdam (7) - A.A.E.A. de Smet, D. Vroegindeweij; Jeroen Bosch Hospital, den Bosch (7) - R.M.M. van Loenhout, M.J. Rutten; St. Elisabeth Hospital, Tilburg (5) — J.F. Hamming, L.E.H. Lampmann; Maxima Medical Center, Veldhoven (5) - M.H.M. Bender, H. Pasmans; Onze Lieve Vrouwe Gasthuis, Amsterdam (5) — A.C. Vahl, C. de Vries; Meander Medical Center, Amersfoort (4) - A.J.C. Mackaay; Vlietland Hospital, Schiedam (4) — L.M.C. van Dortmont; University Medical Center, Nijmegen (4) - A.J. van der Vliet, L.J. Schultze Kool; Martini Hospital, Groningen (3) - J.H.B. Boomsma, H.R. van Dop; Medical Center Haaglanden, 's-Gravenhage (3) - J.C.A. de Mol van Otterloo, T.P.W. de Rooij; Hospital Bernhoven, Oss (3) - T.M. Smits; Oosterschelde Hospital, Goes (3) - E.N. Yilmaz; Vrije Universiteit Medical Center, Amsterdam (2) - W. Wisselink, F.G. van den Berg; Leiden University Medical Center, Leiden (1) M.J.T. Visser, E. van der Linden; University Medical Center, Maastricht (1) - G.W.H. Schurink, M. de Haan; Bronovo Hospital, 's-Gravenhage (1) — H.J. Smeets; Belgium: St. Jozef Hospital, Turnhout (4) — P. Stabel; St. Trudo Hospital, St. Truiden (3) — F. van Elst; University Hospital, Antwerp (1) -J. Poniewierski; University Medical Center, Gent (1) - F.E.G. Vermassen.

REFERENCES

1. Greenhalgh RM, Brown LC, Kwong GP, Powell JT, Thompson SG. Comparison of endovascular aneurysm repair with open repair in patients with abdominal aortic aneurysm (EVAR trial 1), 30-day operative mortality results: randomised controlled trial. Lancet 2004;364:843-8.

2. Prinssen $M$, Verhoeven ELG, Buth J, et al. A randomized trial comparing conventional and endovascular repair of abdomina aortic aneurysms. N Engl J Med 2004;351: 1607-18.

3. Lederle FA. Abdominal aortic aneurysm
- open versus endovascular repair. $\mathrm{N}$ Engl Med 2004;351:1677-9.

4. Maher MM, McNamara AM, MacEneaney PM, Sheehan SJ, Malone DE. Abdominal aortic aneurysms: elective endovascular repair versus conventional surgery - evaluation with evidence-based medicine techniques. Radiology 2003;228:647-58.

5. Harris PL, Vallabhaneni SR, Desgranges P, Becquemin JP, van Marrewijk C, Laheij RJ. Incidence and risk factors of late rupture, conversion, and death after endovascular repair of infrarenal aortic aneurysms: the
EUROSTAR experience. J Vasc Surg 2000; 32:739-49.

6. Prinssen M, Buskens E, Blankensteijn JD. The Dutch Randomised Endovascular Aneurysm Management (DREAM) trial: background, design and methods. J Cardiovasc Surg (Torino) 2002;43:379-84.

7. Rutherford RB, Baker JD, Ernst C, et al. Recommended standards for reports dealing with lower extremity ischemia: revised version. J Vasc Surg 1997;26:517-38. [Erratum, J Vasc Surg 2001;33:805.]

8. ChaikofEL, Blankensteijn JD, Harris PL, 
et al. Reporting standards for endovascular aortic aneurysm repair. J Vasc Surg 2002;35: 1048-60.

9. Goueffic Y, Becquemin JP, Desgranges P, Kobeiter H. Midterm survival after endovascular versus open repair of infrarenal aortic aneurysms. J Endovasc Ther 2005;12 47-57.

10. Cao P, Verzini F, Parlani G, et al. Clinical effect of abdominal aortic aneurysm en dografting: 7-year concurrent comparison with open repair. J Vasc Surg 2004;40:841-8. 11. Zarins CK, Heikkinen MA, Lee ES, Alsac JM, Arko FR. Short- and long-term outcome following endovascular aneurysm repair: how does it compare to open surgery? J Cardiovasc Surg (Torino) 2004;45:321-33.
12. The United Kingdom Small Aneurysm Trial Participants. Long-term outcomes of immediate repair compared with surveillance of small abdominal aortic aneurysms. N Engl J Med 2002;346:1445-52.

13. Norman PE, Semmens JB, LawrenceBrown MM, Holman CD. Long term relative survival after surgery for abdominal aortic aneurysm in western Australia: population based study. BMJ 1998;317:852-6.

14. Eagle KA, Berger PB, Calkins $\mathrm{H}$, et al. ACC/AHA guideline update for periopera tive cardiovascular evaluation for noncardiac surgery - executive summary of a report of the American College of Cardiology American Heart Association Task Force on Practice Guidelines (Committee to Update the 1996 Guidelines on Perioperative Cardiovascular Evaluation for Noncardiac Surgery). Circulation 2002;105:1257-67.

15. Kertai MD, Boersma E, Bax JJ, et al. Optimizing long-term cardiac management after major vascular surgery: role of betablocker therapy, clinical characteristics, and dobutamine stress echocardiography to optimize long-term cardiac management after major vascular surgery. Arch Intern Med 2003;163:2230-5.

16. Kertai MD, Boersma E, Westerhout CM, et al. Association between long-term statin use and mortality after successful abdominal aortic aneurysm surgery. Am J Med 2004;116:96-103.

Copyright (c) 2005 Massachusetts Medical Society. 